\title{
Improved ocean wind forcing products
}

Combining scatterometer observations and numerical weather prediction model winds into global high-resolution 14 ocean strface wind fields

Rianne Giesen ${ }^{1}$, Ana Trindade ${ }^{2,3}$, Marcos Portabella ${ }^{2}$, Ad Stoffelen $^{1}$

1. Royal Netherlands Meteorological Institute, De Bilt, Netherlands

2. Institut de Ciències del Mar, CSIC, Barcelona, Spain

3. Universitat Politecnica de Catalunya, Barcelona, Spain 


\section{Context}

Ocean surface wind fields from satellites (scatterometer) and numerical weather prediction (NWP) models both have strong properties

\begin{tabular}{|rcc|}
\hline & Scat & NWP \\
\hline Spatial resolution & + & - \\
\hline Spatial coverage & - & + \\
\hline Temporal coverage & - & + \\
\hline
\end{tabular}

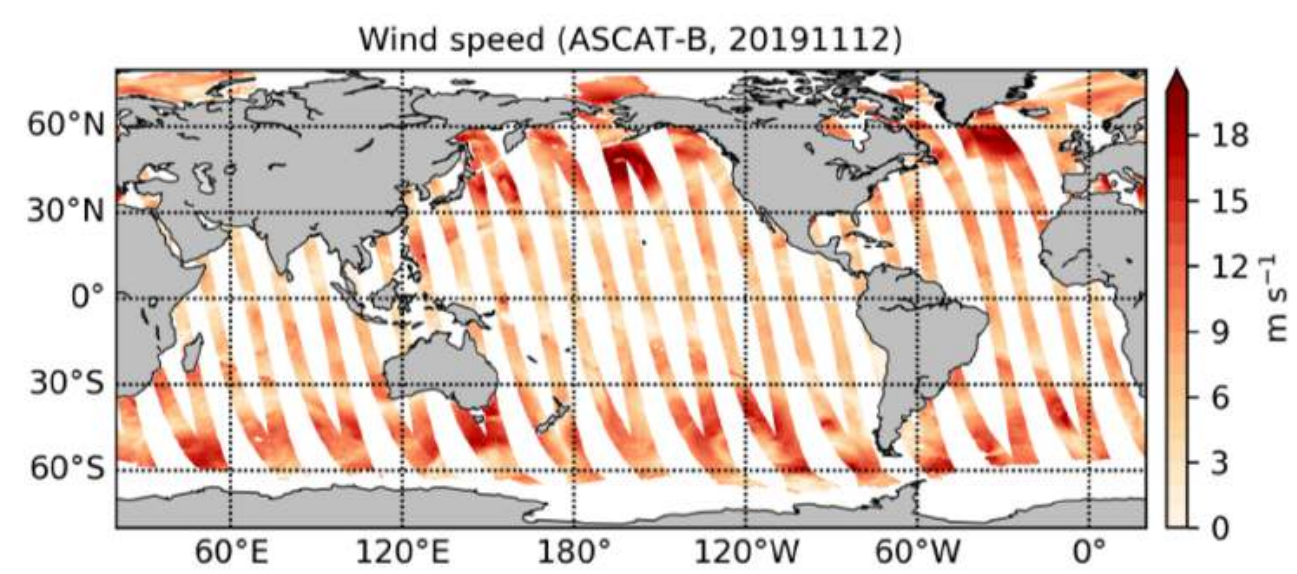

How to best combine scatterometer observations and NWP model fields into global ocean wind forcing products with high temporal and spatial resolution?

$>\quad$ First explore the differences between scatterometer (MetOp-A ASCAT) and NWP model (ECMWF ERA5) 
Systematic large-scale biases in NWP model winds, particularly in the tropics and the mid-latitudes
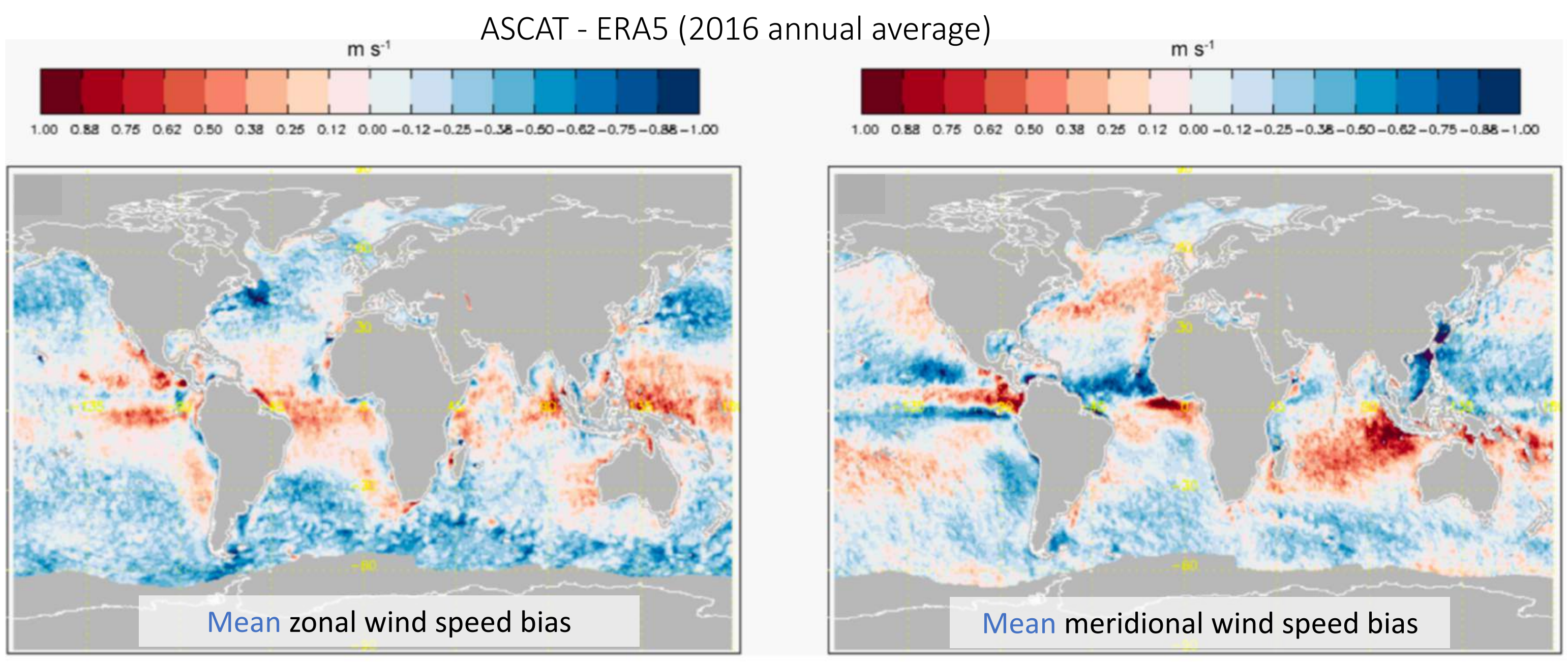

Belmonte Rivas, M. and A. Stoffelen (2019): Characterizing ERA-Interim and ERA5 surface wind biases using ASCAT, Ocean Sci., 15, 831-852, doi: 10.5194/os-15-831-2019. 


\section{Small-scale variability is largely underestimated in NWP model}

ASCAT - ERA5 (2016 annual average)

$\mathrm{m} \mathrm{s}^{-1}$

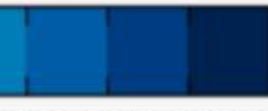

$\begin{array}{llllllllllll}1.00 & 0.88 & 0.75 & 0.62 & 0.50 & 0.38 & 0.25 & 0.12 & 0.00-0.12-0.25-0.38-0.50-0.62-0.75-0.88-1.00\end{array}$
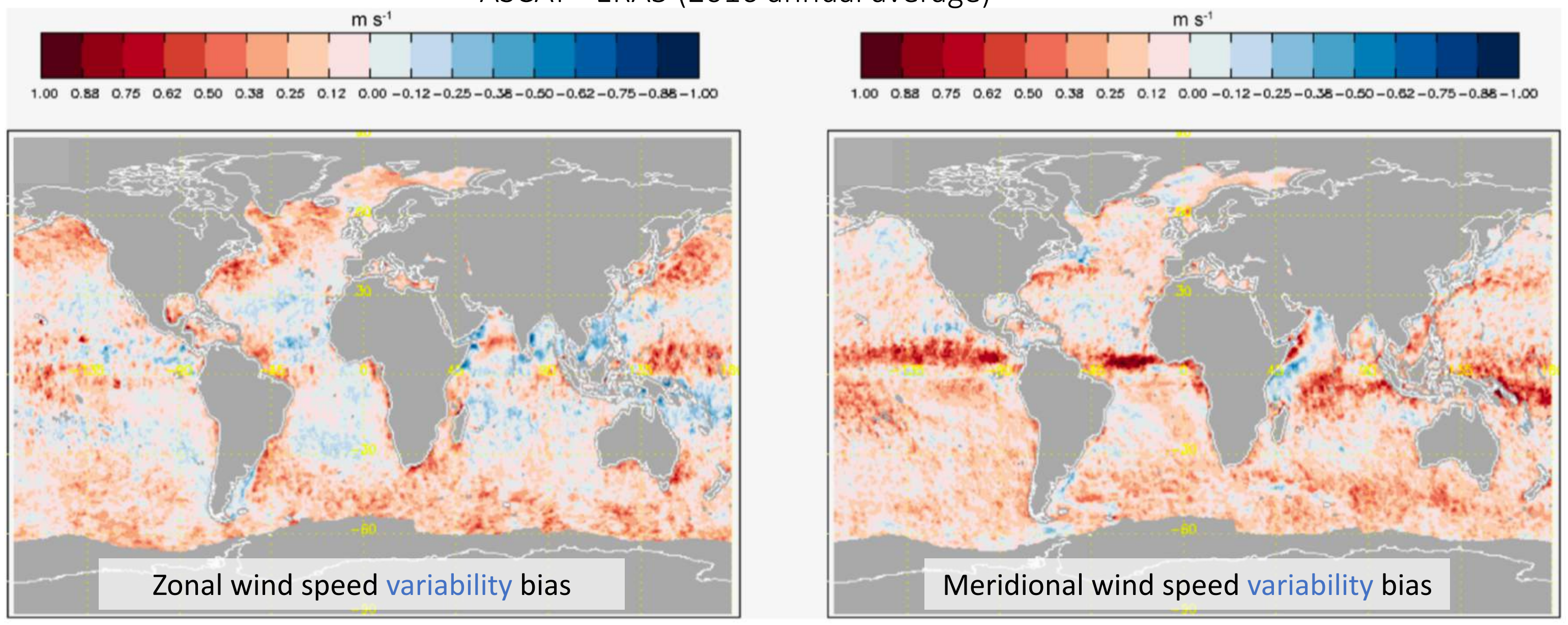

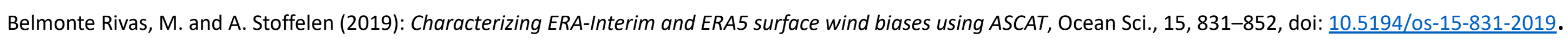




\section{Scatterometer-based correction to ERA-Interim surface wind fields}

$$
S C\left(i, j, t_{f}\right)=1 / M \sum_{t=1}^{M} u_{10 s}^{S C A T}(i, j, t)-u_{10 s}^{E R A i}(i, j, t)
$$

SC Scatterometer-based correction

(i, j) Grid point

$t_{f} \quad$ NWP model forecast time

$M \quad$ Number of scatterometer observations at $(i, j)$ in time window of $N$ days

$t \quad$ Observation time

$u_{10 s}^{S C A T} \quad$ Stress-equivalent wind speed from scatterometer

$u_{10 s}^{E R A i} \quad$ Stress-equivalent wind speed from NWP model interpolated to $(i, j, t)$ 


\section{Example SC}

$90^{\circ} \mathrm{W} \quad 0^{\circ} \quad 90^{\circ} \mathrm{E}$

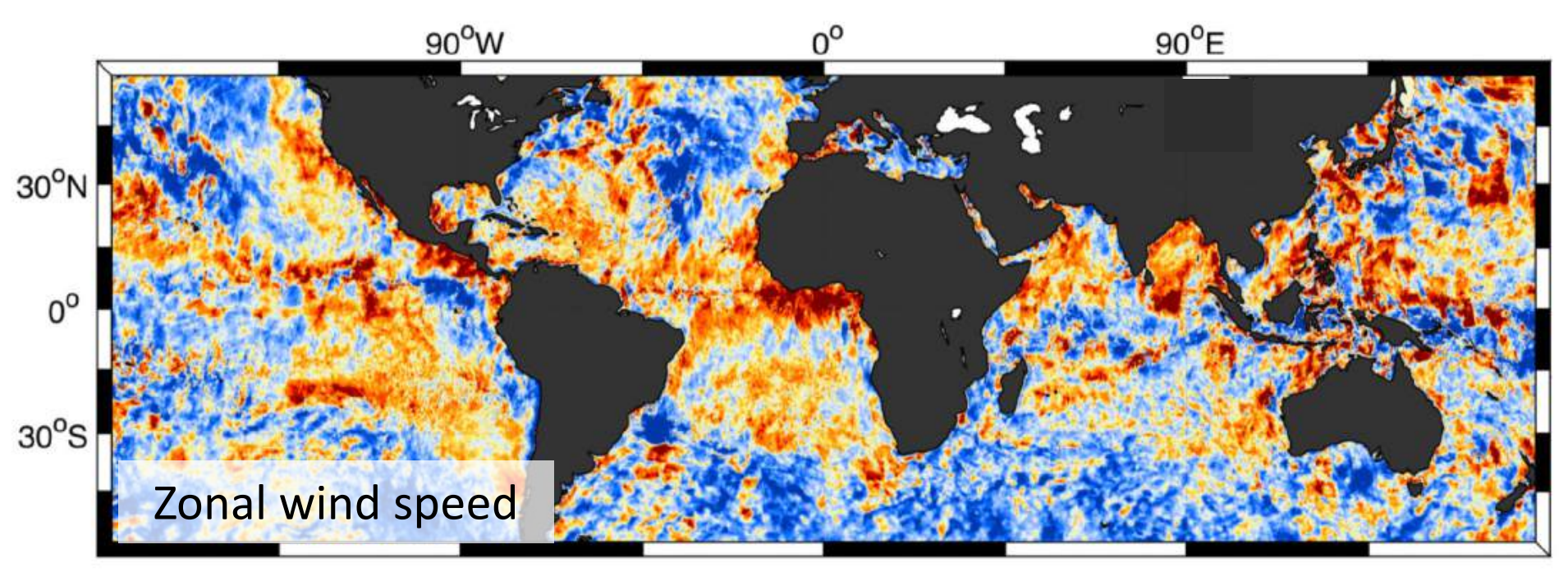

\section{SCAT MetOp-A ASCAT \\ $t_{f} 15$ January 2013, 6 UTC \\ $N 5$ days}

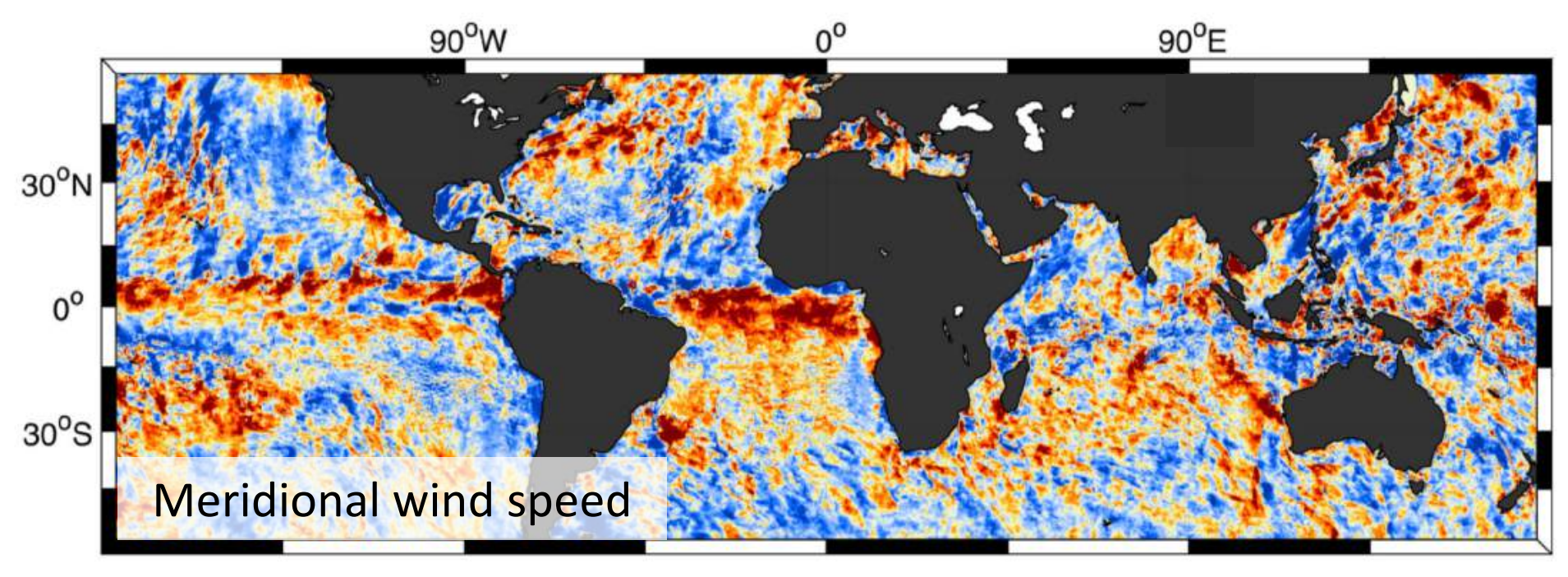

The large systematic biases are associated with slowly evolving ocean conditions, rather than with fast atmospheric processes

m.s ${ }^{-1}$ 


\section{ERA*}

$u_{10 s}^{E R A^{*}}\left(i, j, t_{f}\right)=u_{10 s}^{E R A i}\left(i, j, t_{f}\right)+S C\left(i, j, t_{f}\right)$

\section{Available}

- on a global grid

- at $0.125^{\circ} \times 0.125^{\circ}$ horizontal resolution

- at 3-hourly temporal resolution (ERA-Interim) 


\section{Example ERA*}

\section{SCAT MetOp-A ASCAT MetOp-B ASCAT Oceansat-2 OSCAT \\ $t_{f} 15$ January 2013, 6 UTC \\ $N \quad 1$ day (b) \\ 3 days (c)}
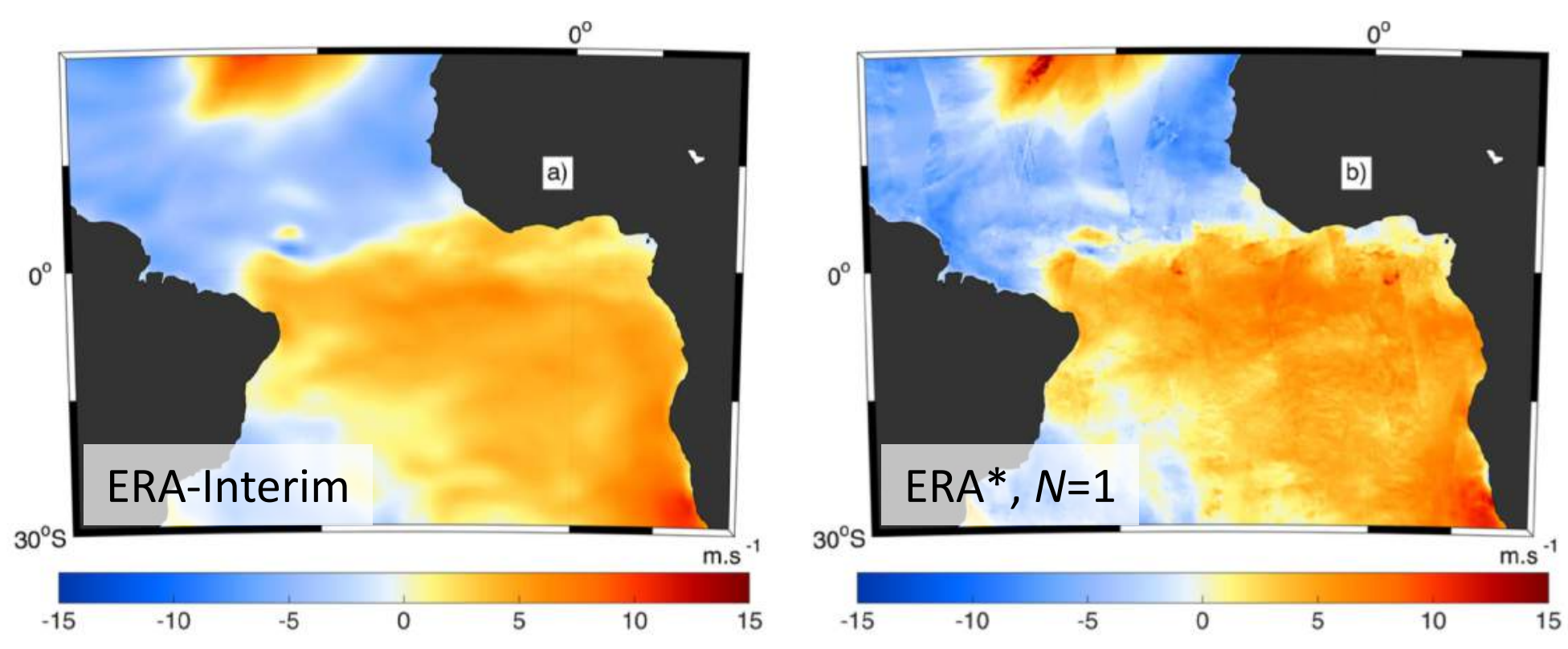

ERA* is less smooth than ERA-Interim

Small-scale variability captured with $N=1$

Artifacts $(\mathrm{N}=1)$ not present with $N=3$

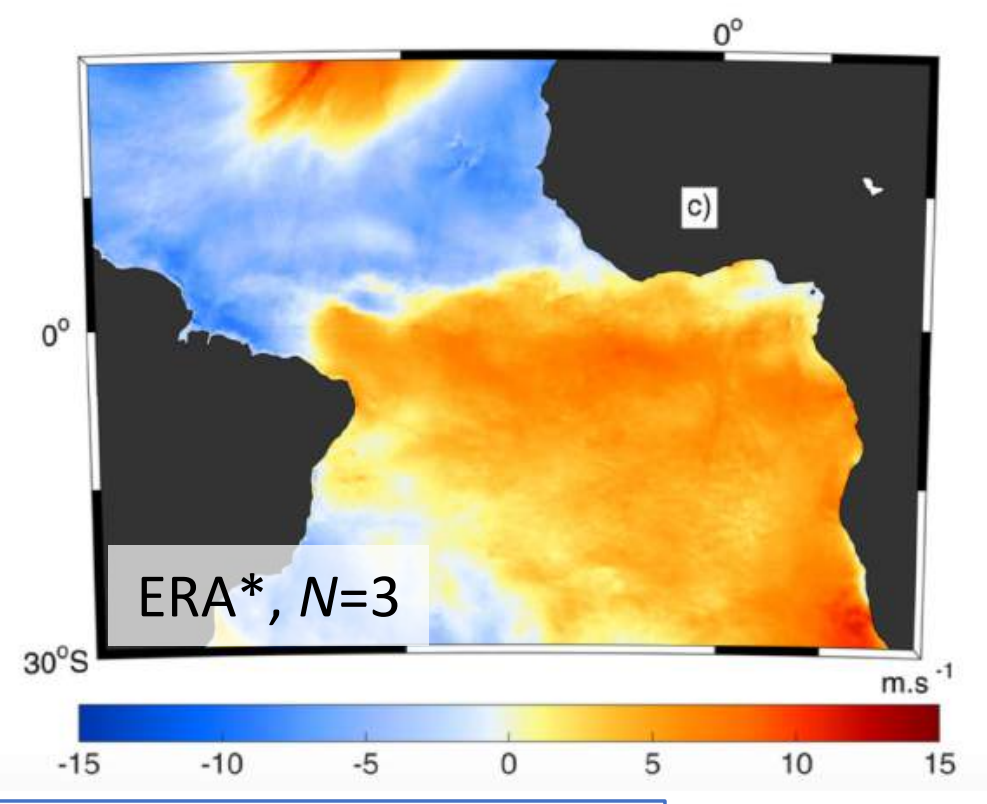

Trindade, A., M. Portabella, A. Stoffelen, W. Lin and A. Verhoef (2019), ERAstar: A High-Resolution Ocean Forcing Product, IEEE Trans. Geosci. Remote Sens., 1-11, doi: 10.1109/TGRS.2019.2946019. 


\section{What are the optimal scatterometer combination and temporal averaging window?}

Vector root-mean-squared difference between ERA* and an independent scatterometer (HY-2A HSCAT) for a number of scatterometer combinations and averaging windows $N$
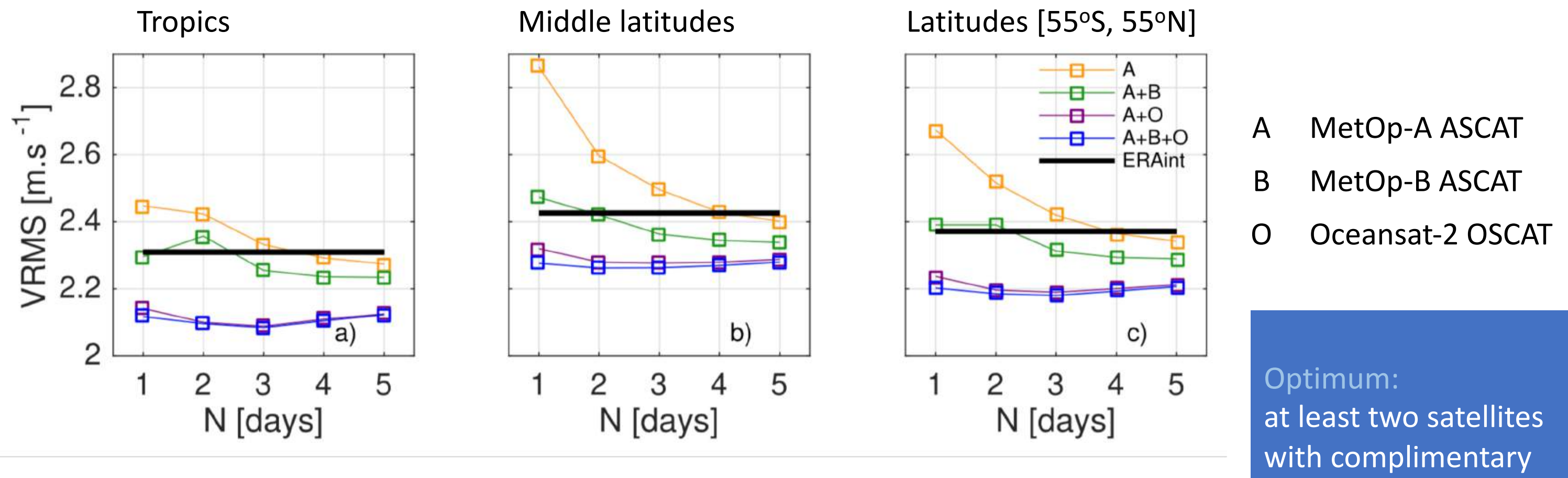

Trindade, A., M. Portabella, A. Stoffelen, W. Lin and A. Verhoef (2019), ERAstar: A High-Resolution Ocean Forcing Product, orbits and $\mathrm{N}=2$ or 3 


\section{Conclusions}

- Large systematic and persistent biases exist between scatterometer observations and NWP model surface wind fields

- NWP model surface winds lack small scales, which also appears persistent

- The scatterometer wind structures express local air-sea interaction, relevant for ocean forcing

- ERA* shows a significant increase in small-scale variability compared to ERA-Interim

- The optimal configuration consists of complementary scatterometers and a temporal averaging window of 2-3 days

- For fewer scatterometers, longer windows can be used, as error growth is rather slow for an increasing number of days

- ERA* has high potential for a Level 4 (CMEMS) wind product 


\section{Outlook}

\section{Short-term}

- Test ERA* wind fields in regional ocean models

- Apply the method to the ECMWF ERA5 dataset > ERA5*

- Compare to existing L4 wind products (CMEMS)

\section{Long-term}

- Work towards ERA* near-real time and multi-year L4 wind products (CMEMS) 


\section{Questions? Contact us!}

1. Chat with Rianne during the live session on Friday 8 May, 10:45-12:30

2. Upload your comments on the EGU2020 website

3. Send an email to Rianne: rianne.giesen@knmi.nl

Link to the session:

https://meetingorganizer.copernicus.org/EGU2020/EGU2020-15559.html 